\title{
PENDIDIKAN ISLAM SEBAGAI GRAND DESIGN PENDIDIKAN KARAKTER
}

\author{
Muhammad Isnaini \\ Dosen Fakultas Tarbiyah, sekarang Ketua Badan Penelitian dan Pengembangan Pendidikan Islam \\ (BP3i) Fakultas Tarbiyah IAIN Raden Fatah Palembang.
}

\begin{abstract}
Character education is a positive offer in the eradication of moral crises which particularly emerged in our students. Therefore, the internalization of values of character education in the educational institution is a must. As an Islamic education institution in Indonesia, the existence of Boarding school is considered to be able to develop values of character education which may be done through formal or non-formal curriculum. This is so because since its early existence, Boarding school has delineated its distinctive feature which is different from the other common types of education. Here, the implementation of character values have been integrated (within large portion) in the religious subjects. Character education, at least in the discourse, still a potent tool in addressing the arious issues that whack this nation. Not only in Indonesia, even in developed countries such as the United States, Germany, Japan, and, still rely on character education as a mainstay of kick to overcome various moral issues at hand. Character education became very warm issue in the education scene in Indonesia due to the rampant cases of moral that afflicts this nation, ranging from scenes in high State institutions, educational nstitutions until those cases that occur in the streets. The cases allegedly due to the failure of education that has lasted until today. Criticisms of the educational world tends to be mechanical, cognitive aspects than prefer the affective and psychomotor, and a series of spicy criticism more have graced the writings of educational expert. In order to respond to these concerns, the Government now, through the Ministry of education and culture and supported by the Ministry of Religion, raised character education agenda as the national education agenda. Sayang sayang thousand, until now there has been no clear concept of philosophy as well as on the technical implementation. This paper will offer solutions to various problems in philosophy as well as the implementation of character education. The author of the theme of humanist-religious is one of spirits in
\end{abstract}


character education. The reason is that to improve the character of a nation, certainly could not depart from values which do not come from the nation itself. Humanist-religious is a character that belongs to the people of Indonesia so that character education is applied in this country inevitably had to depart from this character. After discussing the philosophy of character education from the perspective of humanist-religious, the author offers some alternatives that are related to the stages of education, learning methods, as well as the position of teachers in character education.

Keywords: Character Education, Humanist-Religious

\section{Pendahuluan}

Jauh sebelumnya, secara filosofis "Bapak" Pendidikan Nasional, Ki Hadjar Dewantara, menyatakan bahwa pendidikan merupakan daya upaya untuk memajukan bertumbuhnya budi pekerti (kekuatan batin, karakter), pikiran (intellect) dan tubuh anak. bagian-bagian itu tidak boleh dipisahkan agar kita dapat memajukan kesem-purnaan hidup anak-anak kita. Hakikat, fungsi, dan tujuan pendidikan nasional tersebut menyiratkan bahwa melalui pendidikan hendak diwujudkan peserta didik yang secara utuh memiliki berbagai kecerdasan, baik kecerdasan spiritual, emosional, sosial, intelektual maupun kecerdasan kinestetika.

Pendidikan nasional mempunyai misi mulia (mission sacre) terhadap individu peserta didik. Dalam instrumentasi dan praksis pendidikan nasional sudah dikembangkan program rintisan, walaupun belum secara sistemik menyeluruh, dengan fokus dan muatan yang cukup beragam, misalnya: (1) pengembangan nilai esensial budi pekerti yang dirinci menjadi 85 butir (Dikdasmen: 1989 s/d 2007); (2) pengembangan nilai dan ethos demokratis dalam konteks pengembangan budaya sekolah yang demokratis dan bertanggung jawab (Dikdasmen: $1991 \mathrm{~s} / \mathrm{d}$ 2007); (3) pengembangan nilai dan karakter bangsa (Dikdasmen: 2001-2005); dan (4) pengembangan nilai-nilai anti korupsi yang mencakup jujur, adil, berani, tanggung jawab, mandiri, kerja keras, peduli, sederhana, dan disiplin (Dikdasmen dan KPK; 2008-2009); serta pengembangan nilai dan prilaku keimanan dan ketaqwaan dalam konteks tauhidiyah dan religiositas-sosial (Dikdasmen: 1998-2009). 
Di luar kegiatan tersebut sudah banyak juga sekolah-sekolah unggulan yang mengembangan karakter secara terpadu dalam pelaksanaan pendidikannya. Banyak juga sekolah yang sederhana; pondok pesantren di daerah pedesaan yang mampu menumbuhkembangkan karakter peserta didik budaya sekolah melalui pembiasaan dlm kehidupan keseharian di sekolah/pondok yang ternyata teladan guru/ustadz sebagai kunci sukses. Dalam sarasehan nasional tgl 14 Januari 2010 diketahui bahwa ternyata banyak sekolah yang sudah mengembangkan pendidikan karakter dan ternyata juga dapat meningkatkan prestasi belajar siswa.(Balitbang Diknas:2010). Tantangan ke depan adalah bagaimana berbagi kesukssesan itu untuk membangun pendidikan karakter yang mampu menyentuh semua jalur, jenjang, dan jenis pendidikan di tanah air Indonesia ini.

Secara akademik, pendidikan karakter dimaknai sebagai pendidikan nilai, pendidikan budi pekerrti, pendidikan moral, pendidikan watak, yang tujuannya mengembangkan kemampuan peserta didik untuk memberikan keputusan baik-buruk, memelihara apa yang baik itu, dan mewujudkan kebaikan itu dalam kehidupan sehari-hari dengan sepenuh hati. Karena itu muatan pendidikan karakter secara psikologis mencakup dimensi moral reasoning, moral feeling, dan moral behaviour (Lickona:1991), atau dalam arti utuh sebagai morality yang mencakup moral judgment and moral behaviour baik yang bersifat prohibition-oriented morality maupun pro-social morality (Piager, 1967; Kohlberg; 1975; Eisenberg-Berg; 1981).

Secara pedagogis, pendidikan karakter seyogyanya dikembangkan dengan menerapkan holistic approach, dengan pengertian bahwa "Effective character education is not adding a program or set of programs. Rather it is a tranformation of the culture and life of the school" (Berkowitz: ... dalam goodcharacter.com: 2010): Sementara itu Lickona (1992) menegaskan bahw: "In character education, it's clear we want our children are able to judge what is right, care deeply about what is right, and then do what they believe to be right-even in the face of pressure form without and temptation from within. 
Kebutuhan akan pendidikan karakter ternyata terjadi juga di USA pada saat memasuki abad 21, karena beberapa alasan mendasar sebagai berikut (Lickona, 1991: 20-21)

1. There is a clear and urgent need.

2. Transmitting values is and always has been the work of civilisation.

3. The school's role as moral educator becomes more vital at a time when millions of children get little moral teaching from their parents and when valuecentered influence such as church or temple are also absent from their lives.

4. thereis a common ethical ground even in our values-conflicted society.

5. Democracies have a special need for moral education.

6. There is no such thing as value-free education.

7. Moral questions are among the great question facing both the individuals and human race.

8. There is a broad-based, growing support for values education in the schools

Dari situasi tersebut bahwa pendidikan nilai/moral memang sangat diperlukan atas dasar argumen: adanya kebutuhan nyata dan mendesak; proses tranmisi nilai sebagai proses peradaban; peranan sekolah sebagai pendidik moral yang vital pada saat melemahnya pendidikan nilai dalam masyarakat; tetap adanya kode etik dalam masyarakat yang sarat konflik nilai; kebutuhan demokrasi akan pendidikan moral; kenyataan yang sesungguhnya bahwa tidak ada pendidikan yang bebas nilai; persoalan moral sebagai salah satu persoalan dalam kehidupan, dan adanya landasan yang kuat dan dukungan luas terhadap pendidikan moral di sekolah. Smua argumen tersebut tampaknya masih relevan untuk menjadi cerminan kebutuhan akan pendidikan nilai/moral di Indonesia pada saat ini. Proses demokasi yang semakin meluas dan tantangan globalisasi yang semakin kuat dan beragam disatu pihak dan dunia persekolahan dan pendidikan tinggi yang lebih mementingkan penguasaan dimensi pengetahuan dan mengabaikan pendidikan nilai/moral saat ini, merupakan alasan yang kuat bagi Indonesia untuk membangkitkan komitmen dan melakukan gerakan nasional pendidikan karakter. Lebih jauh dari itu adalah Indonesia dengan 
masyarakatnya yang ber-Bhinneka tunggal ika dan dengan falsafah negaranya Pancasila yang sarat dengan nilai dan moral, merupakan alasan filosofikideologis, dan sosial-kultural tentang pentingnya pendidikan karakter untuk dibangun dan dilaksanakan secara nasional dan berkelanjutan.

Karena itu, pengembangan nilai yang bermuara pada pembetukan karakter bangsa yang diperoleh melalui berbagai jalur, jenjang, dan jenis pendidikan, akan mendorong mereka menjadi anggota masyarakat, anak bangsa, dan warga negara yang memiliki kepribadian unggul seperti diharapkan dalam tujuan pendidikan nasional. Sampai saat ini, secara kurikuler telah dilakukan berbagai upaya untuk menjadikan pendidikan lebih mempunyai makna bagi individu yang tidak sekadar memberi pengetahuan pada tataran koginitif, tetapi juga menyentuh tataran afektif dan konatif melalui mata pelajaran Pendidikan Agama, Pendidikan Kewarganegaraan, Pendidikan IPS, Pendidikan Bahasa Indonesia, dan Pendidikan Jasmani.

\section{Perangkat Nilai Substansi Pendidikan Karakter}

Dalam Permendiknas N0.23/2006 tentang Standar kompetensi lulusan secara formal sudah digariskan untuk masing-masing jenis atau satuan pendidikan sejumlah rumusan Standar Kompetensi Lulusan (SKL). Jika diremati secara mendalam, sesungguhnya hampir pada setiap rumusan SKL tersebut implisit atau eksplisit termuat substansi nilai/karakter. Berikut ini dicoba untuk menangkap substansi nilai/karakter yang ada pada setiap SKL tersebut. Nilai-nilai Substansi Nilai/Karakter yang ada pada SKL SD/MI/ SMP/MTs/SMA/MA serta SMK adalah sebagai beruikut :

\begin{tabular}{|c|l|l|}
\hline No. & \multicolumn{1}{|c|}{ Rumusan SKL } & Nilai/Karakter \\
\hline I & $\begin{array}{l}\text { Menjalankan ajaran agama yang dianut sesuai dengan tahap } \\
\text { perkembangan anak }\end{array}$ & Iman dan taqwa \\
\hline 2 & Mengenal kekurangan dan kelebihan diri sendiri & jujur \\
\hline 3 & $\begin{array}{l}\text { Mematuhi aturan-aturan sosial yang berlaku dalam } \\
\text { lingkungannya }\end{array}$ & disiplin \\
\hline
\end{tabular}




\begin{tabular}{|c|c|c|}
\hline No. & Rumusan SKL & Nilai/Karakter \\
\hline 4 & $\begin{array}{l}\text { Menghargai keberagaman agama, budaya, suku, ras, dan } \\
\text { golongan sosial ekonomi di lingkungan sekitarnya }\end{array}$ & $\begin{array}{l}\text { Terbuka, } \\
\text { nasionalistik }\end{array}$ \\
\hline 5 & $\begin{array}{l}\text { Menggunakan informasi tentang lingkungan sekitar secara } \\
\text { logis, kritis, dan kreatif }\end{array}$ & Bernalar, kreatif \\
\hline 6 & $\begin{array}{l}\text { Menunjukkan kemampuan berpikir logis, kritis, dan kreatif, } \\
\text { dengan bimbingan guru/pendidik }\end{array}$ & Bernalar, kreatif \\
\hline 7 & $\begin{array}{l}\text { Menunjukkan rasa keingintahuan yang tinggi dan menyadari } \\
\text { potensinya }\end{array}$ & Terbuka, bernalar \\
\hline 8 & $\begin{array}{l}\text { Menunjukkan kemampuan memecahkan masalah sederhana } \\
\text { dalam kehidupan sehari-hari }\end{array}$ & bernalar \\
\hline 9 & $\begin{array}{l}\text { Menunjukkan kemampuan mengenali gejala alam dan sosial } \\
\text { di lingkungan sekitar }\end{array}$ & Terbuka, bernalan \\
\hline IO & $\begin{array}{l}\text { Menunjukkan kecintaan dan kepedulian terhadap } \\
\text { lingkungan }\end{array}$ & $\begin{array}{l}\text { Peduli, tanggung } \\
\text { jawab }\end{array}$ \\
\hline II & $\begin{array}{l}\text { Menunjukkan kecintaan dan kebanggaan terhadap bangsa, } \\
\text { negara, dan tanah air Indonesia }\end{array}$ & nasionalistik \\
\hline I2 & $\begin{array}{l}\text { Menunjukkan kemampuan untuk melakukan kegiatan seni } \\
\text { dan budaya lokal }\end{array}$ & $\begin{array}{l}\text { Kreatif, tanggung } \\
\text { jawab }\end{array}$ \\
\hline I3 & $\begin{array}{l}\text { Menunjukkan kebiasaan hidup bersih, sehat, bugar, aman, } \\
\text { dan memanfaatkan waktu luang }\end{array}$ & $\begin{array}{l}\text { Bersih, tanggung } \\
\text { jawab }\end{array}$ \\
\hline I4 & Berkomunikasi secara jelas dan santun & Santun \\
\hline I5 & $\begin{array}{l}\text { Bekerja sama dalam kelompok, tolong-menolong, dan } \\
\text { menjaga diri sendiri dalam lingkungan keluarga dan teman } \\
\text { sebaya }\end{array}$ & $\begin{array}{l}\text { Gotong royong, } \\
\text { peduli }\end{array}$ \\
\hline I6 & Menunjukkan kegemaran membaca dan menulis & gigih \\
\hline I7 & $\begin{array}{l}\text { Menunjukkan keterampilan menyimak, berbicara, } \\
\text { membaca, menulis, dan berhitung }\end{array}$ & bernalar \\
\hline
\end{tabular}

Secara psikologis dan sosial-kultural, pembentukan karakter dalam diri individu merupakan fungsi dari seluruh potensi individu manusia (kognitif, afektif, konatif, dan psikomotorik) dalam konteks interaksi sosial kultural (dalam keluarga, sekolah, dan masyarakat) dan berlangsung sepanjang hayat. Konfigurasi karakter dalam konteks totalitas proses psikologis dan sosialkultural tersebut dapat dikelompokan dalam: Olah Hati (Spiritual and emotional development), Olah Pikir (intellectual development), Olah Raga dan Kinestetik 
(Physical and kinestetic development), dan Olah Rasa dan Karsa ( Affective and Creativity development) yang secara diagramatik dapat digambarkan sebagai berikut.

\section{Strategi Pengembangan Pendidikan Karakter pada Pendidikan Makro dan Mikro}

Pengembangan nilai/karakter dapat dilihat pada dua latar/domain, yaitu pada latar makro dan latar mikro. Latar makro bersifat nasional yang mencakup keseluruhan konteks perencanaan dan ilmpementasi pengembangan nilai/karakter yang melibatkan seluruh pemangku kepentingan pendidikan nasional. Pada latar makro program pengembangan nilai/karakter dapat digambarkan sebagai berikut.

Gambar I. Konteks Makro Pengembangan Karakter

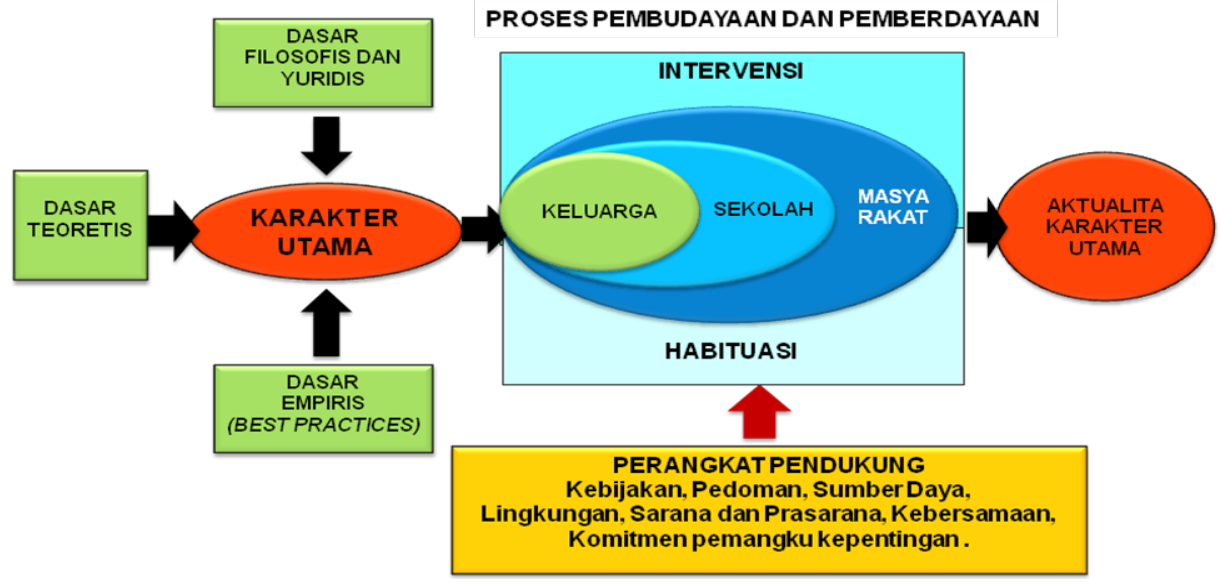

Secara makro pengembangan karakter dapat dibagi dalam tiga tahap, yakni perencanaan, pelaksanaan, dan evaluasi hasil. Pada tahap perencanaan dikembangkan perangkat karakter yang digali, dikristalisasikan, dan dirumuskan dengan menggunakan berbagai sumber, antara lain pertimbangan: (1) filosofis - Agama, Pancasila, UUD 1945, dan UU N0.20 Tahuin 2003 beserta ketentuan perundang-undangan turunannya;(2) pertimbangan teoritis- teori tentang otak, psikologis, nilai dan moral, pendidikan (pedagogi dan andragogi) dan sosial-kultural; dan (3) pertimbangan empiris berupa 
pengalaman dan praktek terbaik (best practices) dari antara lain tokoh-tokoh, sekolah unggulan, pesanren, kelompok kultural dll.

Pada tahap implementasi dikembangakan pengalaman belajar (learning experiences) dan proses pembelajaran yang bermuara pada pembentukan karakter dalam diri individu peserta didik. Proses ini dilaksanakan melalui proses pembudayaan dan pemberdayaan sebagaimana digariskan sebagai salah satu prinsip penyelenggaraan pendidikan nasional. Proses ini berlangsung dalam tiga pilar pendidikan yakni dalam sekolah, keluarga, dan masyarakat. Dalam masing-masing pilar pendidikan akan ada dua jenis pengalaman belajar (learning experiences) yang dibangun melalui dua pendekatan yakni intervensi dan habituasi. Dalam intervensi dikembangkan suasana interaksi belajar dan pembelajaran yang sengaja dirancang untuk mencapai tujuan pembentulkan karakter dengan menerapkan kegiatan yang terstruktur (structured learning experiences). Sementara itu dalam habituasi diciptakan situasi dan kondisi (persistence life situation) yang memungkinkan peserta didik di sekolahnya, di rumahnya, di lingkungan masyarakatnya membiasakan diri berprilaku sesuai nilai dan menjadi karakter yang telah diinternalisasi dan dipersonalisai dari dan melalui proses intervensi. Kedua proses tersebut- intervensi dan habituasi harus dikembangkan secara sistemik dan holistik.

Pada tahap evaluasi hasil, dilakukan asesmen untuk perbaikan berkelanjutan yang sengaja dirancang dan dilaksanakan untuk mendikteksi aktualisasi karakter dalam diri peserta didik sebagai indikator bahwa proses pembudayaan dan pemberdayaan karakter itu berhasil dengan baik.

Pada konteks mikro pengembangan karakter berlangsung dalam konteks suatu satuan pendidikan atau sekolah secara holistik (the whole school reform). Sekolah sebagai leading sector, berupaya memanfaatkan dan memberdayakan semua lingkungan belajar yang ada untuk menginisiasi, memperbaiki, menguatkan, dan menyempurnakan secara terus menerus proses pendidikan karakter di sekolah. Program pengembangan karakter pada latar mikro dapat digambarkan sebagai berikut. 
Gambar 2. Konteks Mikro Pengembangan Nilai/Karakter

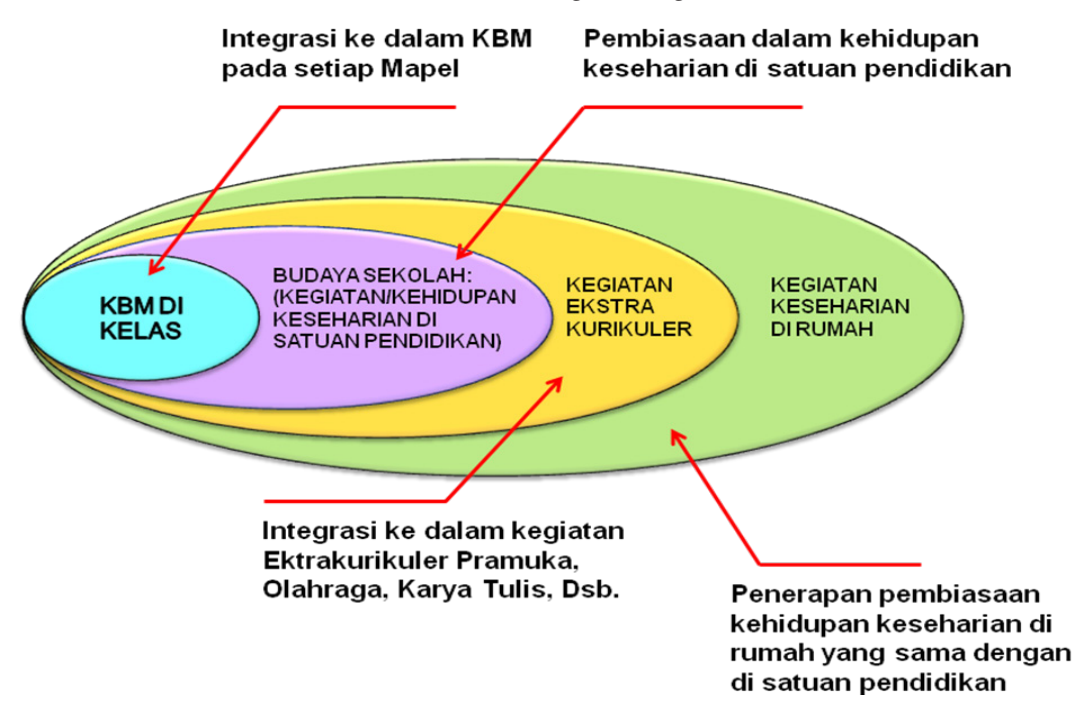

Secara mikro pengembangan nilai/karakter dapat dibagi dalam empat pilar, yakni kegiatan belajar-mengajar di kelas, kegiatan keseharian dalam bentuk budaya sekolah (school culture); kegiatan ko-kurikuler dan/atau ekstra kurikuler, serta kegiatan keseharian di rumah, dan dalam masyarakat.

Dalam kegiatan belajar-mengajar di kelas pengembangan nilai/ karakter dilaksanakan dengan menggunakan pendekatan terintegrasi dalam semua mata pelajaran (embeded approach). Khususu, untuk mata pelajaran Pendidikan Agama dan Pendidikan Kewarganegaraan, karena memang misinya adalah mengembangkan nilai dan sikap maka pengembangan nilai/karakter harus menjadi fokus utama yang dapat menggunakan berbagai strategi/metode pendidikan nilai (value/character education). Untuk kedua mata pelajaran tersebut nilai/karakter dikembangkan sebagai dampak pembelajaran (instructional effects) dan juga dampak pengiring (nurturant effects). Sementara itu untuk mata pelajaran lainnya, yang secara formal memiliki misi utama selain pengembangan nilai/karakter, wajib dikembangkan kegiatan yang memiliki dampak pengiring (nurturant effects) berkembangnya nilai/karakter dalam diri peserta didik. 
Dalam lingkungan sekolah dikondisikan agar lingkungan fisik dan sosialkultural sekolah memungkinkan para peserta didik bersama dengan warga sekolah lainnya terbiasa membangun kegiatan keseharian di sekolah yang mencerminkan perwujudan nilai/karakter. Dalam kegiatan ko-kurikuler, yakni kegiatan belajar di luar kelas yan g terkait langsung pada suatu materi dari suatu mata pelajaran, atau kegiatan ekstra kurikuler, yakni kegiatan sekolah yang bersifat umum dan tidak terkait langsung pada suatu mata pelajaran, seprti kegiatan Dokter Kecil, Palang Merah Remaja, Pecinta Alam dll, perlu dikembangkan proses pembiasaan dan penguatan (reinforcement) dalam rangka pengembangan nilai/karakter.

Di lingkungan keluarga dan masyarakat diupayakan agar terjadi proses penguatan dari orang tua/wali serta tokoh-tokoh masyarakat terhadap prilaku berkarakter mulia yang dikembangkan di sekolah menjadi kegiatan keseharian di rumah dan di lingkungan masyarakat masing-masing.

Konteks mikro pengembangan nilai/karakter merupakan latar utama yang harus difasilitasi bersama oleh Pemerintah Daerah dan Kementrian Pendidikan Nasional. Dengan demikian terjadi proses sinkronisasi antara pengembangan nilai/karakter secara psiko-pedagogis di kelas dan di lingkungan sekolah, secara sosio-pedagogis di lingkungan sekolah dan masyarakat, dan pengembangan nilai/karakter secara social-kultural nasional. Untuk itu sekolah perlu difasilitasi untuk dapat mengembangkan budaya sekolah (school culture). Pengembangan budaya sekolah ini perlu menjadi bagian integral dari pengembangan sekolah sebagai entitas otonom seperti dikonsepsikan dalam managemen berbasis sekolah (MBS). Dengan demikian, setiap satuan pendidikan secara bertahap dan sistemik ditumbuhkembangkan menjadi sekolah-sekolah yang dinamis dan maju (self-renewal schools) (Purkey dan Novak: 1990)

\section{Integrasi Nilai Pendidikan Islam dalam Kegiatan Intrakurikuler dan Kokulikuler \\ Perencanaan dan pelaksanaan pendidikan budaya dan karakter bangsa dilakukan oleh kepala sekolah, guru, tenaga kependidikan (konselor) secara}


bersama-sama sebagai suatu komunitas pendidik diterapkan ke dalam kurikulum melalui kegiatan-kegiatan sebagai berikut.

\section{Program Pengembangan Diri}

Dalam program pengembngan diri, perencanaan dan pelaksanaan pendidikan budaya dan karakter bangsa dilakukan melalui pengintegrasian kedalam kegiatan sehari-hari sekolah yaitu melalui hal-hal sebagai berikut.

\section{a. Kegiatan rutin sekolah}

Kegiatan rutin merupakan kegiatan yang dilakukan peserta didik secara terus menerus dan konsisten setiap saat. Contoh kegiatan ini adalah: upacara pada hari besar kenegaraan, pemeriksaan kebersihan badan (kuku, telinga, rambut dan lain-lain) setiap hari Senin, beribadah bersama/sembahyang bersama setiap dluhur (bagi yang beragama Islam), berdoa waktu mulai dan selesai pelajaran, mengucap salam bila bertemu guru/tenaga kependidikan yang lain dan sebagainya.

\section{b. Kegiatan spontan}

Kegiatan spontan yaitu kegiatan yang dilakukan secara spontan pada saat itu juga. Kegiatan ini dilakukan biasanya pada saat guru dan tenaga kependidikan yang lain mengetahui adanya perbuatan yang kurang baik dari peserta didik yang harus dikoreksi pada saat itu juga. Apabila guru mengetahui adanya perilaku dan sikap yang kurang baik maka pada saat itu juga guru harus melakukan koreksi sehingga peserta didik tidak akan melakukan tindakan yang tidak baik tersebut. Contoh kegiatan tersebut adalah: membuang sampah tidak pada tempatnya, berteriak-teriak sehingga mengganggu pihak lain, berkelahi, melakukan bullying, memalak, berlaku tidak sopan, mencuri, berpakaian tidak senonoh dan sebagainya.

Kegiatan spontan berlaku untuk perilaku dan sikap peserta didik yang tidak baik dan yang baik sehingga perlu dipuji, misalnya: memperoleh nilai tinggi, menolong orang lain, memperoleh prestasi 
dalam olahraga atau kesenian, berani menentang/mengkoreksi perilaku teman yang tidak terpuji dan sebagainya.

\section{c. Teladan}

Keteladanan adalah perilaku dan sikap guru dan tenaga kependidikan yang lain dalam memberikan contoh terhadap tindakantindakan yang baik sehingga diharapkan menjadi panutan bagi peserta didik untuk mencontohnya. Jika guru dan tenaga kependidikan yang lain menghendaki agar peserta didik berperilaku dan bersikap sesuai dengan nilai-nilai budaya dan karakter bangsa maka guru dan tenaga kependidikan yang lain adalah orang yang pertama dan utama memberikan contoh bagaimana berperilaku dan bersikap sesuai dengan nilai-nilai terebut. Misalnya berpakaian rapi, datang tepat pada waktunya, bekerja keras, bertutur kata sopan, kasih sayang, perhatian terhadap peserta didik, jujur, menjaga kebersihan dan sebagainya.

\section{d. Pengkondisian}

Untuk mendukung keterlaksanaan pendidikan budaya dan karakter bangsa maka sekolah harus dikondisikan sebagai pendukung kegiatan tersebut. Sekolah harus mencerminkan kehidupan sekolah yang mencerminkan nilai-nilai dalam budaya dan karakter bangsa yang diinginkan. Misalnya toilet yang selalu bersih, bak sampah ada di berbagai tempat dan selalu dibersihkan, sekolah terlihat rapi dan alat belajar ditempatkan teratur.

\section{Pengintegrasian dalam semua Mata Pelajaran}

Pengembangan nilai-nilai dan karakater diintegrasikan dalam setiap pokok bahasan dari setiap mata pelajaran. Nilai-nilai tersebut dicantumkan dalam Silabus dan Rencana Program Pembelajaran (RPP). Pengembangan nilai-nilai tersebut dalam Silabus ditempuh melalui cara-cara sebaghai berikut

a. mengkaji Standar Kompetensi (SK) dan Kompetensi Dasar (KD) untuk menentukan apakah kandungan nilai-nilai dan karakter yang 
secara tersirat atau tersurat dalam SK dan KD di atas sudah tercakup di dalamnya

b. menggunakan tabel 1 yang memperlihatkan keterkaitan antara SK/ KD dengan nilai dan indikator untuk menentukan nilai yang akan dikembangkan

c. mencantumkankan nilai-nilai dan karakter bangsa dalam tabel 1 tersebut ke dalam silabus

d. mencantumkan nilai-nilai yang sudah tercantum dalam silabus ke RPP

e. mengembangkan proses pembelajaran peserta didik aktif yang memungkinkan peserta didik memiliki kesempatan melakukan internalisasi nilai dan menunjukkannya dalam perilaku yang sesuai

f. memberikan bantuan kepada peserta didik yang mengalami kesulitan untuk internalisasi nilai mau pun untuk menunjukkannya dalam perilaku.

Praktik pendidikan karakter di sekolah bukan hanya menjadi tanggungjawab mata pelajaran Agama atau Pendidikan Kewarganegaraan (PKn). Selama ini ada kesan mata pelajaran yang lain hanya mengajarkan pengetahuan sesuai dengan bidangnya ilmu, teknologi atau seni. Padahal seharusnya proses pembelajaran nilai-nilai karakter idealnya diintegrasikan di dalam setiap mata pelajaran atau mengintegrasikan nilai-nilai karakter ke dalam antar mata pelajaran. Fenomena seperti itu yang tampaknya menjadi alasan Charles Handy (2006), seorang bussiness philosopher, yang menganjurkan untuk merombak total pendidikan. Dalam artikel berjudul Finding Sense in Uncertainty, dia menjelaskan pendidikan selama ini berangkat dari asumsi yang keliru, yaitu bahwa semua problem di dunia ini telah diketahui dan guru mengetahui cara pemecahannya. Jadi tugas guru dipersepsikan hanya menyampaikan problem serta cara pemecahannya, dan setelah itu pendidikan dianggap selesai.

Padahal senyatanya, problema itu terus berubah dan tentu guru belum mengetahui, apalagi cara memecakannya. Charles Handy 
menegaskan belajar tentang ilmu pengetahuan tetap penting, tetapi hal itu kini lebih mudah dilakukan, karena banyak sumber informasi yang dapat dipelajari. Oleh karena itu, pendidikan seharusnya diarahkan untuk membantu siswa belajar bagaimana memperoleh ilmu pengetahuan itu dan yang tidak kalah penting adalah apa yang harus dilakukan dengan ilmu pengetahuan itu. Distu tersisat perlunuya karakter sebagai wahana perwujudan dimensi aksiologi dari berilmu. Dari situ dapa disim[pulkan bahwa pendidikan seharusnya diarahkan untuk mengembangkan kemampuan siswa dalam memperoleh pengetahuan dan bagaimana menggunakannya guna memecahkan problema kehidupan dengan arif, kreatif, dan bertanggung jawab.

Persoalannya kini adalah bagaimana hubungan antara pedidikan karakter dengan mata pelajaran? Keduanya tetap diperlukan dan harus saling melengkapi. Dalam pengembangan pendidikan karakter, seharusnya mata pelajaran dipahami sebagai pesan dan alat (as medium and message) yaitu sebagai wahana pembudayaan dan pemberdayaan individu.. Misalnya Guru Fisika harus sadar bahwa pembahasan materi Fisika diarahkan untuk mengembangkan kemampuan siswa dalam memahami fenomena alam dari sudut pandang teori Fisika, menggali berbagai sumber informasi dan menganalisisnya untuk menyempurnakan pemahaman tersebut, mengkomunikasikan pemahaman tersebut kepada orang lain, dan memahami bahwa fenomena seperti itu tidak lepas dari "peran" Sang Pencipta. Pengembangan pendidikan karakter seperti itu, dapat dilakukan melalui metoda pembelajaran yang dipilih guru. Misalnya, untuk mengembangkan kecakapan berkomunikasi, guru dapat memilih metoda diskusi atau siswa diminta presentasi. Untuk mengembangkan kecakapan bekerja sama, disiplin, kerja kelompok dalam praktikum dapat diterapkan. Yang penting adalah bahwa aspekaspek tersebut sengaja dirancang dan dinilai hasilnya sebagai bentuk hasil belajar pendidikan karakter.

Ada banyak cara mengintergrasikan nilai-nilai karakter ke dalam mata pelajaran, antara lain: Mengungkapkan nilai-nilai yang 
dalam mata pelajaran, pengintegrasian langsung di mana nilai-nilai kakater menjadi bagian terpadu dari mata pelajaran, menggunakan perumpamaan dan membbuat perbandingan dengan kejadian-kejadian serupa dalam hidupp para siswa, mengubah hal-hal negatif menjadi nilai positif, mengungkapakan nilai-nilai melalui diskusi dan brainstroming, Menggunakan cerita untuk memunculkan nilai-nilai, mnceritakan kisahh hidup orang-orang besar, menggunakan lagu-lagu dan musik untuk mengintegrasikan nilai-nilai, menggunakkann drama untuk melukiskan kejadian-kejadian yang berisikan nilai-nilai, menggunakan berbagai kegiatan seperti kegiatan pelayanan, field trip dan klub-klub atau kelompok kegiatan untuk memunculkan nilai-nilai kemanusiaan.

\section{Pembiasaan Perilaku bermuatan Nilai Pendidikan Islam}

Dalam kehidupan sehari-hari di sekolah, sekolah harus menerapkan totalitas pendidikan dengan mengandalkan keteladanan, penciptaan lingkungan dan pembiasaan melalui berbagai tugas dan kegiatan. Sehingga seluruh apa yang dilihat, didengar, dirasakan dan dikerjakan oleh siswa adalah pendidikan. Selain menjadikan keteladanan sebagai metode pendidikan utama, penciptaan miliu juga sangat penting. Lingkungan pendidikan itulah yang ikut mendidik. Penciptaan lingkungan disekolah dapat dilakukan melalui : 1) penugasan, 2) pembiasaan, 3) pelatihan, 4) pengajaran, 5) pengarahan, serta 6) keteladanan.Semuanya mempunyai pengaruh yang tidak kecil dalam pembentukan karakter anak didik. Pemberian tugas tersebut disertai pemahaman akan dasar-dasar filosofisnya, sehingga anak didik akan mengerjakan berbagai macam tugas dengan kesadaran dan keterpanggilan. Setiap kegiatan mengandung unsurunsur pendidikan, sebagai contoh dalam kegiatan kepramukaan, terdapat pendidikan kesederhanaan, kemandirian, kesetiakawanan dan kebersamaan, kecintaan pada lingkungan dan kepemimpinan. Dalam kegiatan olahraga terdapat pendidikan kesehatan jasmani, penanaman sportivitas, kerja sama (team work) dan kegigihan untuk berusaha. Pengaturan kegiatan di sekolah ditangani oleh organisasi pelajar yang terbagi dalam banyak bagian, seperti Ketua, Sekretaris, Bendahara, Keamanan, Pengajaran, Penerangan, Koperasi 
Pelajar, Koperasi Dapur, Kantin Pelajar, Bersih Lingkunan, Pertamanan, Kesenian, Ketrampilan, Olahraga, Penggerak Bahasal.

Kegiatan kepramukaan juga ditangani oleh Koordinator Gerakan Pramuka dengan beberapa andalan; Ketua Koordinator Kepramukaan, Andalan Koordinator Urusan Kesekretariatan, Andalan Koordinator Urusan Keuangan, Andalan Koordinator Urusan Latihan, Andalan Koordinator Urusan Perpustakaan, Andalan Koordinator Urusan Perlengkapan, Andalan Koordinator Urusan Kedai Pramuka, dan Pembina gugusdepan. Pendidikan organisasi ini sekaligus untuk kaderisasi kepemimpinan melalui pendidikan self government. Sementara itu pada level asrama ada organisasi sendiri, terdiri dari ketua asrama, bagian keamanan, penggerak bahasa, kesehatan, bendahara dan ketua kamar. Setiap club olah raga dan kesenian juga mempunyai struktur organisasi sendiri, sebagaimana konsulat (kelompok wilayah asal santri) juga dibentuk struktur keorganisasian. Seluruh kegiatan yang ditangani organisasi pelajar ini dikawal dan dibimbing oleh para senior mereka yang terdiri dari para guru staf pembantu pengasuhan santri, dengan dukungan guru-guru senior yang menjadi pembimbing masing-masing kegiatan. Secara langsung kegiatan pengasuhan santri ini diasuh oleh Bapak Pimpinan Pondok yang sekaligus sebagai Pengasuh Pondok.

Pengawalan secara rapat, berjenjang dan berlapis-lapis ini dilakukan oleh para santri senior dan guru, dengan menjalankan tugas pengawalan dan pembinaan, sebenarnya mereka juga sedang melalui sebuah proses pendidikan kepemimpinan, karena semua sisswa, terutama siswa senior dan guru adalah kader yang sedang menempuh pendidikan. Pimpinan pondok membina mereka melalui berbagai macam pendekatan; pendekatan program, pendekatan manusiawi (personal) dan pendekatan idealisme. Mereka juga dibina, dibimbing, didukung, diarahkan, dikawal, dievaluasi dan ditingkatkan. Demikianlah pendidikan karakter yang diterapkan d sekolah melalui berbagai macam kegiatannya. Kegiatan yang padat dan banyak akan menumbuhkan dinamika, dinamika yang tinggi akan membentuk militansi dan militansi yang kuat akan menimbulkan etos kerja dan produktivitas. 
Pada akhirnya anak didik akan mempunyai kepribadian yang dinamis, aktif, dan produktif dalam segala kebaikan.

Kehidupan sehari-hari di rumah dan di masyarakat perlu juga mendapat perhatian dalam rangka pendidikan karakter.Banyak manfaat yang bisa diperoleh oleh sekolah dari masyarakat dan sebaliknya yang bisa diperoleh oleh masarakat dari hadirnya sekolah itu. Antara sekolah dan masarakat harus mengadakan banyak interaksi. Beberapa komponen masyarakat yang bisa terlibat dalam proses belajar d sekolah yaitu: orangtua, masyarakat. Peran Orang tua. Agar model pembelajaran nilai-nilai karakter bisa berhasil dengan baik, kita membutuhkan orang tua yang benar-benar menjadi partner yang berkomitmen tinggi terhadap proses belajar anak-anak mereka. Orangtua adalah guru di rumah, karenanya mereka harus menganut visi yang sama dengan sekolah demikian pula dengan tujuan sekolah. Orangtua mesti setuju dengan tujuan sekolah untuk menghasilkan anakanak yang baik yang memeiliki nilai-nilai kemanusiaan. Sekolah seyogyanya memberikan pelatihan menegnai human values parenting atau menjadi orang tua yang baik kepada semua ayah, ibu atau yang mengantar anak-anak ke sekolah. Ketika siswa berada d rummah, orang tua mesti meluangkan waktu bertemu bersama anak-anak mereka dan memebrikan cinta kasih dan kehangatan. Orang tua dan guru mesti mengadakan pertemuan reguer untuk mendisuksikan masalah-masalah yang dihadapi siswa dan mesti membuat trencana untuk membantu memecahkan masalah-masalah itu. Para orangtua harus berpartisipasi dalam berbagai kegiatan di sekolah dan membagikan pengetahuan dan pengalaman mereka kepada para siswa dan guru.

Komunitas atau masyarakat sekitar memiliki peran penting dalam pembentukan karakter anak. Sekolah harus dipandang sebagai suatu sistem hidup yang terus menerus tumbuh dan berkembang. Sekolah juga sedang dalam proses belajar karena selalu ada interaksi antara setiap orang di sekolah dan komunitas. Guru dan siswa selalu berhubungan dengan orangtua dan kerabat mereka di masyarakat. Berbagai kegiatan yang dilakukan orang ta dapat memainkan peranan penting dalam pengembangan sekolah. Setiap oran di sekolah termasuk semua staf sangat dipengaruhi oleh temapt-tempat 
ibadah, komunitas pasar, perkantoran dll sebagainya. Sebagai bagian dari pembelajaran, siswa harus blajar melayani komunitas atau masyarakat dalam pegembangannya. Mereka mesti turut serta dalam kegiatan pelayanan yang diadakan di tempat-tempat ibadah. Sekolah mesti membantu komunitas untuk mengembangkan dan membantu pendidikan orang-orang dalam komunias. Ketika komunitas tersebut menjadi sebuat komunitas belajar atau learning communities, sekolah akan mendapatkan manfaat besar dari komunitas seperti ini.

\section{Penutup}

Dalam konteks ini, maka pengembangan karakter bangsa lebih ditekankan pada kegiatan internalisasi dan pembentukan tingkah laku. Dan untuk kepentingan ini, maka tidak relevan untuk menciptakan kurikulum baru tentang pengembangan karakter, namun lebih menekankan dengan menciptakan lingkungan dan tingkah laku. Dengan mengacu pada referensi maka setiap sekolah diwajibkan untuk mempunyai statuta yang didalamnya dicantumkan secara eksplisit dan jelas tentang pengembangan karakater di sekolah tersebut. Dengan statuta tersebut maka kegiatan pengembangankarakter dapat dituntun dan diketahui oleh Pengelola Sekolah, baik oleh Kepala Sekolah maupun oleh Komite Sekolah.

Setiap statuta sekolah akan mencamntumkan nilai-nilai dasar (core values) yang merupakan ciri khas karakter Bangsa Indonesia, yang bersumbar dari nilai-nilai agama maupun dari jiwa nasionalisme atau patriotisme. Nilainilai dasar tersebut adalah jujur, dapat dipercaya, kebersamaan, peduli kepada orang lain, adil, demokratis, toleransi. Nilai-nilai yang substantif tersebut kemudian dikembangkan dalam satuan-satuan pendidikan sesuai dengan "local wisdom", selaras dengan nilai-nilai lokal setempat dalam polapola yang lebih detail. Misalnya, cara menghormati atau cara bersopan santun kepada orng lain, cara bertata krama, cara guru memberikan sangsi kepada murid, dan sebagainya. Dalam hal ini, maka perhatian kepada siswa menjadi sangat urgent sebab mereka yang segera akan turun dalam dunia nyata yang berupa masyarakat. Nilai-nilai semacam tersebut di atas harus 
dilakukan berulang-ulang agar menjadi kebiasaan, dan kebiasaan inilah yang akan menjadi budaya setempat.

Untuk kepentingan ini maka tiap satuan pendidikan, harus meiliki buku saku yang berupa pedoman ringkas sehingga bersifat mengikat (otoritaitf) sebab idusun dengan kesepakaan bersama. Dengan demikian maka para murid, para guru, para orang tua akan melakukan hal tersebut secara sinergis. Di setiap satuan pendidikan akan memiliki "code of conduct", "manner management" serta "organizational culture" yang diperlukan dalam peroses pengambangan karakater tersebut.

\section{DAFTAR PUSTAKA}

Agustian, Ary Ginanjar, 2007, Membangun Sumber Daya Manusia dengan Kesinergisan antara Kecerdasan Spiritual, Emosional, dan Intelektual. Pidato Ilmiah Penganugerahan Gelar Kehormatan Doctor Honoris Causa di Bidang Pendidikan Karakter, UNY.

Azra, Azyumardi, 2006, Agama, Budaya, dan Pendidikan Karakter Bangsa.

Djalil, Sofyan A. dan Megawangi, Ratna. Peningkatan Mutu Pendidikan di Aceh melalui Implementasi Model Pendidikan Holistik Berbasis Karakter. Makalah Orasi Ilmiah pada Rapat Senat Terbuka dalam Rangka Dies Natalis ke 45 Universitas Syiah Kuala Banda Aceh, 2 September 2006.

Elkind, David H. dan Sweet, Freddy. How to Do Character Education. Artikel yang diterbitkan pada bulan September/Oktober 2004.

Jalal, Fasli dan Supriadi, Dedi, 2001, Reformasi Pendidikan dalam Konteks Otonomi Daerah, Adicita Karya Nusa,.

Lickona, Thomas, 1992, Educating for Character: How Our Schools Can Teach Respect and Responsibility, Yogyakarta: Bantam Books, New York.

Lickona, Tom; Schaps, Eric, dan Lewis, Catherine, 2007, Eleven Principles of Effective Character Education. Character Education Partnership.

Pimpinan Pusat Muhammadiyah, 2009, Revitalisasi Visi dan Karakter Bangsa, Yogyakarta: PP Muhammadiyah.

Sairin, Weinata, 2001, Pendidikan yang Mendidik, Jakarta: Yudhistira 
160 | AR-RIWAYAH, Volume 7, Nomor 1, April 2015

Suyanto dan Hisyam, Djihad, 2000, Pendidikan di Indonesia Memasuki Milenium III: Refleksi dan Reformasi, Yogyakarta: Adicita Karya Nusa

Suyatno; Sumedi, Pudjo, dan Riadi, Sugeng (Editor), 2009, Pengembangan Profesionalisme Guru: 70 Tahun Abdul Malik Fadjar, Jakarta: UHAMKA Press.

U. S. Department of Education, Office of Safe and Drug-Free Schools. Washington, DC: 400 Maryland Avenue, S.W. 